\title{
ENSINO DE LÍNGUA PORTUGUESA NA EDUCAÇÃO DE JOVENS E ADULTOS EM SITUAÇÃO DE PRIVAÇÃO DE LIBERDADE: PRIMEIRAS APROXIMAÇÕES ${ }^{1}$
}

\author{
Carolina Fabricia Narciso ${ }^{2}$ \\ Rosângela Pedralli ${ }^{3}$
}

\begin{abstract}
Resumo
Este artigo apresenta as indicações para o ensino de Língua Portuguesa/Materna nos espaços de privação de liberdade do Estado de Santa Catarina, presentes nos documentos que orientam a educação no Estado. A partir de uma investigação de cunho bibliográfico e considerando a Teoria Histórico-Cultural como base teórico-metodológica dos documentos orientadores, este trabalho retrata as indicações contidas neles, a saber: a Proposta Curricular de Santa Catarina (2014); o Plano estadual de educação em prisões 2016-2026: educação, prisão e liberdade, diálogos possíveis (2017) e o Projeto Político-Pedagógico - CEJA Centro Florianópolis (2018, 2019) e apresenta, através de dados numéricos, a atual situação educacional, em geral, desses espaços, com o objetivo de aproximar futuros docentes e pesquisadores ao contexto e especificidades da área de Educação de Jovens e Adultos nesses espaços, apresentando-os, também, como um dos muitos possíveis para a carreira do magistério. A análise de tais documentos dá conta de certo distanciamento das indicações com a concepção de formação humana integral presente na Proposta Curricular de Santa Catarina, assim como a ausência quanto ao tratamento específico das orientações para o ensino de Língua Portuguesa/Materna. Palavras-chave: EJA. Ensino de Língua. Formação humana integral. Privação de liberdade
\end{abstract}

\section{TEACHING PORTUGUESE LANGUAGE IN THE EDUCATION OF YOUTH AND ADULTS IN A SITUATION OF DEPRIVATION OF LIBERTY: FIRST} APPROACHES

\begin{abstract}
This article presents the indications for teaching Portuguese/Maternal Language in spaces of deprivation of liberty in the State of Santa Catarina, present in the documents that guide education in the State. Based on a bibliographical investigation and considering the HistoricalCultural Theory as the theoretical-methodological basis of the guiding documents, this work portrays the indications contained in the documents, namely: the Curriculum Proposal of Santa
\end{abstract}

\footnotetext{
${ }^{1} \mathrm{O}$ presente artigo trata de um recorte da pesquisa, apresentada como Trabalho de Conclusão de Curso de Graduação em Letras - Língua Portuguesa e Literaturas na UFSC, intitulada Ensino de língua na Educação de Jovens e Adultos em situação de privação de liberdade: elementos para pensar a formação humana a partir de uma abordagem histórico-cultural. Nela, a autora faz uma análise crítica, a partir de uma investigação de cunho bibliográfico, das indicações para o ensino de Língua Portuguesa/Materna contidas nos documentos orientadores para o trabalho educativo nas unidades prisionais do Estado de Santa Catarina (NARCISO, 2019).

${ }^{2}$ Universidade Federal de Santa Catarina-UFSC, Florianópolis -Santa Catarina, Brasil. Mestranda pelo Programa de Pós-Graduação em Linguística da UFSC e integrante do Grupo de Estudos e Pesquisas em Educação Linguística (GEPEL/FURG-UFSC). Bolsista da CAPES. <ORCID orcid.org/0000-0003-4178-9918>. E-mail: fnarciso.carolina@gmail.com

${ }^{3}$ Universidade Federal de Santa Catarina -UFSC, Florianópolis -Santa Catarina, Brasil. Doutora em Linguística Aplicada (UFSC). Docente do Programa de Pós-Graduação em Linguística da Universidade Federal de Santa Catarina (PPGLin/UFSC). Vice-líder do Grupo de Estudos e Pesquisas em Educação Linguística (GEPEL/FURGUFSC). ORCID < orcid.org/0000-0002-0698-7032>. E-mail rosangelapedralli@ hotmail.com
} 
Catarina (2014); the State Plan for Education in Prisons 2016-2026: Education, Prison and Freedom, Possible Dialogues (2017) and the Political-Pedagogical Project - CEJA Centro Florianópolis $(2018,2019)$ and presents, through numerical data, the current educational situation, in general, these spaces, with the aim of bringing future teachers and researchers closer to the context and specificities of the area of Youth and Adult Education in these spaces, also presenting them as one of many possible for a teaching career. The analysis of such documents reveals a certain distance between the indications and the concept of integral human formation present in the curriculum proposal of Santa Catarina, as well as the absence of specific treatment of the guidelines for teaching Portuguese/Maternal Language.

Keywords: EJA. Language Teaching. Integral human formation. Deprivation of freedom.

\section{INTRODUÇÃ̃o}

Pensar e debater sobre educação nos tempos atuais ainda é um desafio e pensar sobre a educação em espaços de privação de liberdade é especialmente desafiador, por constituir-se em um campo em que se exacerbam as contradições e os contrastes sociais.

Desde a criação do sistema prisional no Brasil, a discussão e a implementação de questões voltadas à educação dentro das unidades prisionais se deram a partir de publicações como as Normas Gerais do Regime Penitenciário (BRASIL, 1957), a Lei de Execução Penal (BRASIL, 1984), que conduziu a oferta, nos estabelecimentos penais, de assistência educacional aos sujeitos privados de liberdade e das poucas políticas públicas elaboradas para esses espaços.

No Estado de Santa Catarina, as disposições sobre a oferta de ensino dentro do sistema ocorrem a partir da publicação da Lei Complementar 170/1998 ${ }^{4}$ (SANTA CATARINA, 2004), que instituiu, por exemplo, a elaboração de currículos específicos para as demandas dos aprisionados. Além disso, a Resolução no 110/2012, elaborada pelo Conselho Estadual de Educação, definiu as Diretrizes operacionais para a oferta de educação para jovens e adultos em situação de privação de liberdade nos estabelecimentos penais do Estado de Santa Catarina (CEE, 2012, p. 01), e atribuiu, assim, a responsabilidade de oferta de ensino à Secretaria de Educação do Estado, definindo, também, as orientações específicas para elaboração do Projeto Pedagógico desses espaços.

Atualmente, além das diretrizes orientadoras, o Estado de Santa Catarina possui, como documento orientador, o Plano Estadual de Educação em Prisões - PEEP/SC (2016-2026), elaborado de forma coletiva para apresentar à sociedade metas e estratégias estabelecidas para,

\footnotetext{
${ }^{4}$ A Lei 170/1998 foi modificada pela Lei complementar 263/2004, que fez a inclusão de comunidades quilombolas em seu texto e favoreceu a colaboração dos movimentos sociais para a elaboração de políticas públicas educacionais.
} 
neste caso, proporcionar a melhoria e a ampliação da oferta de uma educação de qualidade nos espaços de privação de liberdade; A Proposta Curricular de Santa Catarina ${ }^{5}$ (PCSC, 2014), documento elaborado coletivamente por consultores e profissionais em atuação na Educação Básica em Santa Catarina, que está, atualmente, em sua quinta edição; e os Projetos PolíticoPedagógicos, que orientam as práticas pedagógicas das diversas Unidades Descentralizadas do CEJA, como a Escola Supletiva da Penitenciária ${ }^{6}$ de Florianópolis, unidade educativa explorada no presente artigo através do Projeto Político-Pedagógico do Centro de Ensino de Jovens e Adultos - CEJA Centro de Florianópolis, que, neste artigo, tomaremos como objeto de análise.

Tendo presente este conjunto de diretrizes e encaminhamentos para o projeto educacional estadual, os quais, em linhas gerais, convergem em pelo menos um ponto, a defesa de uma educação de base humanista ${ }^{7}$, que fundamenta a educação no Estado desde a década de 1990, este artigo se propõe a apresentar as indicações para o ensino de Língua Portuguesa/Materna contidas nos documentos orientadores.

Nesse sentido, exatamente por partirmos do contexto catarinense, a análise documental presente neste artigo é pautada em uma perspectiva histórico-cultural e nas possibilidades da educação formal presente nos espaços de privação de liberdade concorrerem a uma educação que se caracteriza como integral, não apenas pela escolha teórica pautada na escola de Vigotsky (1997), mas também, como já citado, por ser essa a perspectiva adotada historicamente pelos documentos do Estado, visto que "O Estado de Santa Catarina, em suas múltiplas propostas curriculares (a da Rede Estadual e de Redes Municipais), enfatiza a formação humana integral" (SANTA CATARINA, 2019, p.12).

Assim, este artigo não busca elaborar uma discussão profunda acerca dos processos de ensino e aprendizagem, de metodologias adequadas ou não, à realidade dos espaços de privação de liberdade de Santa Catarina, mas de apresentar esses espaços como um dos muitos possíveis, para a carreira do magistério e, para além disso, conceber as unidades prisionais como ambientes educativos que potencialmente projetam emancipação e libertação humanas.

Desta forma, assumindo a pesquisa bibliográfica como procedimento técnicoinstrumental (GAMBOA, 2018) em sua relação com os pressupostos teórico-filosóficos que

\footnotetext{
${ }^{5}$ A última atualização da Proposta Curricular, publicada no final de 2019, segue as orientações elencadas na Base Nacional Comum Curricular e mantém, até certo ponto, a perspectiva teórico-filosófica eleita pelo Estado, a Teoria Histórico-Cultural de orientação marxista.

6 A expressão "Escola da Penitenciária", utilizada neste artigo, refere-se ao apelido atribuído à Unidade descentralizada do Centro de Educação de Jovens e Adultos presente no local.

${ }^{7}$ Concebemos, neste artigo, a educação de base humanista, como aquela que converge no que compete à defesa dos direitos humanos.
} 
orientam o ensino de língua no Estado, tomada também como etapa fundamental para a elaboração do conhecimento científico em educação e como metodologia coerente para investigação e análise da realidade, este artigo é dividido em cinco partes: i) a presente introdução, em que são apesentados, de forma geral, algumas diretrizes e encaminhamentos do projeto educacional em espaços de privação de liberdade nacional e estadual, juntamente com a apresentação metodológica e dos documentos orientadores do projeto educacional de Santa Catarina; ii) seção de conteúdo I, em que destacamos as orientações para o trabalho educativo com Língua Portuguesa/Materna presentes na Proposta Curricular de Santa Catarina - PCSC (2014), além da subseção que trata da atualização realizada em 2019; iii) seção de conteúdo II, em que discutimos as orientações contidas no Plano Estadual de Educação em Prisões (2017); iv) seção de conteúdo III, em que apresentamos e analisamos as orientações contidas no Projeto Político-Pedagógico - CEJA Centro Florianópolis - PPP (2018/2019) e v) considerações finais, momento em que buscamos refletir acerca da convergência das indicações analisadas e da escassez de indicações quanto ao tratamento específico das orientações para o ensino de língua nos espaços de privação de liberdade do Estado e de outras problemáticas que envolvem a modalidade de ensino.

\section{EDUCAÇÃO NO SISTEMA PENITENCIÁRIO CATARINENSE EM NÚMEROS}

Buscando abarcar todas as modalidades e espaços de educação formal, em 2017, o governo estadual apresentou propostas e metas para promover o processo educativo e de ressocialização de apenados no estado, que já detém uma alta taxa de presos em regime de trabalho, buscando também ampliar o padrão de referência educacional nacional - conforme dados do IDEB (BRASIL, 2019) -, para além da sala de aula "normal", dentro do sistema prisional e em todas as áreas da educação (SANTA CATARINA, 2017).

De acordo com o Plano Estadual de Educação em Prisões (2017), o Estado de Santa Catarina possui cinquenta estabelecimentos penais, estimando um total de $23.470^{8}$ pessoas privadas de liberdade, desde o Regime Provisório até o Regime Fechado. Segundo o documento, do total de estabelecimentos, os que possuem oferta de educação totalizam quarenta e um. Destes, quase metade (20) é composta por presídios, seguido por (12) Unidades Prisionais Avançadas (UPA) e (7) penitenciárias.

\footnotetext{
${ }^{8}$ Dados atualizados a partir do Painel Interativo do Levantamento Nacional de Informações Penitenciárias, julho a dezembro de 2019. Disponível em: https://bit.ly/34Ve0CF.
} 
É importante destacar que os estabelecimentos denominados presídios são designados a acolher as pessoas que aguardam julgamento, ou seja, voltado para as pessoas presas provisoriamente, conforme determina a Lei de Execução Penal (BRASIL, 1984).

Com relação aos profissionais de educação que atendem a rede estadual de educação nesta modalidade, apenas dois (02) deles possuem Contrato de Trabalho em Caráter Efetivo; o restante do corpo docente, composto por 460 professores, possui Contrato de Admissão em Caráter Temporário (ACT), este com validade de dois anos.

Para todas as modalidades de ensino (Ensino Fundamental, Ensino Médio e EJA), o processo seletivo dos ACTs, realizado de forma bienal, não possui distinção. Assim, o mesmo concurso também engloba a educação dentro das unidades prisionais do Estado.

É importante destacar que a Secretaria de Estado da Educação - SED também oferece aos profissionais que atuam no EJA cursos de formação continuada, mas que ocorrem, de modo geral, também sem distinção no tratamento das especificidades de cada uma das modalidades de ensino.

Quanto às vagas educacionais aos estabelecimentos penais oferecidas pelo Estado de Santa Catarina, atualmente são oferecidas um total de 2.433 vagas, que são distribuídas entre o Ensino Fundamental (Anos Iniciais e Finais) e Ensino Médio.

Os dados aqui apresentados são retratados no Plano Estadual de Educação em Prisões (2017), visto que, no processo de comparação com os dados disponibilizados pelo Conselho Nacional de Justiça - CNJ (BRASIL, 2014), a partir do Relatório Mensal do Cadastro Nacional de Inspeções nos Estabelecimentos Penais ${ }^{9}$, foi possível perceber certa divergência entre alguns dados numéricos retratados. Por esta razão, utilizamos apenas os dados do documento elaborado pelo Estado.

Quanto aos números da oferta de ensino nessas instalações, é possível perceber que a quantidade de vagas disponíveis atualmente não supre a demanda do Estado, este, que atende $2.451^{10}$ apenados de $14.007^{11}$ pessoas que estão nas unidades prisionais com oferta de educação, computando apenas $17,49 \%$ de cobertura total.

Mesmo considerando a significativa necessidade de avanço em relação à abrangência da educação no sistema prisional do estado, evidenciada pelos números alcançados pelos

\footnotetext{
${ }^{9}$ É possível consultar o relatório elaborado pelo CNJ em: https://bit.ly/2SdzSDd.

${ }^{10} \mathrm{O}$ documento mostra que são disponibilizadas 2.433 vagas e, atendidas, são 2.451 pessoas.

${ }^{11}$ É importante ressaltar que o dado da população carcerária, retirado do documento do Estado, está desatualizado. Conforme atualização elaborada no início desta seção, a partir dos dados do Painel Interativo do Levantamento Nacional de Informações Penitenciárias, são 2.451 atendimentos para 23.470 pessoas privadas de liberdade, ou seja, uma cobertura total de $10,44 \%$.
} 
atendimentos, vale ressaltar que, neste artigo, tal constatação não será objeto de nossa elaboração teórica. Centraremos nosso enfoque, como já mencionado, às indicações para a educação em linguagem depreensíveis dos documentos que orientam a educação prisional no âmbito de Santa Catarina.

\section{A PROPOSTA CURRICULAR DO ESTADO E SEU FUNDAMENTO TEÓRICO- METODOLÓGICO}

A Proposta Curricular de Santa Catarina (PCSC), que orienta majoritariamente a educação no Estado, está em sua quinta edição que, em todas elas, fora elaborada coletivamente por consultores e profissionais em atuação na Educação Básica, dentre elas, a edição de 2014, Proposta Curricular de Santa Catarina: formação integral na educação básica, analisada neste artigo, e a atualização de 2019, que busca a efetivação da implementação da Base Nacional Comum Curricular (BNCC).

O documento aqui analisado, mantendo a coerência entre as atualizações, é norteado fortemente pelo pensamento de base marxista e toma a Teoria Histórico-Cultural e Teoria da Atividade como fundamento teórico-metodológico. Assim, conforme orienta a PCSC, busca-se uma alternativa de currículo escolar que supere os modelos de educação tecnicista e aproximese a uma abordagem educativa que favoreça as dimensões histórica e social, de base humanista, portanto (SANTA CATARINA, 2014).

Dentro da perspectiva da Teoria Histórico-Cultural, a PCSC toma a concepção de formação humana integral como ponto principal para nortear suas orientações metodológicas, visando um processo formativo que considere a liberdade, a autonomia e a emancipação como propósitos, a fim de possibilitar o pleno desenvolvimento humano e a apropriação do conhecimento e de aspectos da cultura de forma ativa e crítica (SANTA CATARINA, 2014).

A partir dessa perspectiva, a PCSC orienta para a elaboração de um currículo escolar integrado, que ultrapasse as fronteiras de conhecimentos disciplinares, sem, contudo, rejeitar a importância e a especificidade de cada campo disciplinar, encaminhando-se para o desenvolvimento de currículos que favoreçam a superação de processos formativos fragmentados, ofertando, assim, um processo de incorporação de conhecimentos sob a lógica da humanização.

Segundo o documento, é a partir do currículo integrado, que haverá a ampliação do repertório cultural de cada sujeito, realizado através da apropriação das produções humanas 
historicizadas pelas gerações anteriores (SANTA CATARINA, 2014). Assim, entende-se que é durante o Percurso Formativo e, também, a partir da apropriação de diferentes manifestações culturais que o desenvolvimento em aproximação à integralidade humana seria favorecido. Dessa forma, orienta para a organização de um currículo escolar que contemple o contexto diverso da sala de aula. A partir disso, a prática pedagógica deve levar em conta para além do contexto diverso, buscando desenvolver atividades a partir das individualidades e características de cada sujeito "sejam elas físicas/motoras, emocionais/afetivas, artísticas, linguísticas, expressivo-sociais, cognitivas, dentre outras, contribuindo assim para o desenvolvimento do ser humano de forma omnilateral" (SANTA CATARINA, 2014, p.31).

Pensando nisso, o documento propõe um trabalho pedagógico alinhado à Teoria Histórico-Cultural e às Diretrizes Curriculares Nacionais para a Educação Básica, organizado a partir das individualidades de cada ambiente educacional. Orienta, portanto, para a elaboração de um Projeto Político-Pedagógico (PPP) que possua, em seu núcleo, uma definição clara e concisa de sua orientação teórica-metodológica e seus objetivos, pois este é o instrumento que contribuiria para uma relação entre a comunidade e a esfera escolar e é a partir da efetiva organização curricular, que a escola tem oportunidade de desempenhar a sua função social (SANTA CATARINA, 2014). Nesses termos, a PCSC propõe que professores e educadores, de maneira geral, reflitam como a estrutura e a organização do ambiente escolar possui significativa importância para a efetivação de projeto educacional alinhado à integralidade dos sujeitos, buscando a partir da reformulação de conceitos e de práticas arraigadas na esfera escolar, apontar que é a partir da compreensão das singularidades de cada contexto e de demandas específicas que deve ser eleita a forma e método mais apropriados de organização escolar.

Em síntese, o documento frisa a importância da valorização dos conhecimentos prévios trazidos a partir das diferentes esferas sociais dos sujeitos, as quais podem e devem servir "como ponto de partida para a ampliação dos conhecimentos sistematizados", do pensamento teórico e crítico (SANTA CATARINA, 2014, p. 49). Em boa medida, nessa direção, o documento contempla as discussões afetas à Diversidade e apresenta tal conceito como uma das características dos seres humanos, que deve ser respeitada, sendo considerada um dos aspectos fundamentais para uma formação em consonância com a perspectiva integral (SANTA CATARINA, 2014).

Desta forma, conforme postula a PCSC, a atividade docente deve ser ancorada no conceito de Diversidade apresentado, e deve-se buscar uma prática educativa que esteja 
apoiada na igualdade de direitos, na democracia e fundamentada nas diretrizes legais que norteiam a Educação Básica no território brasileiro.

\section{1 ÁREA DE LINGUAGENS}

A Proposta Curricular de Santa Catarina (2014) apresenta a área de Linguagens dividida em duas seções principais: (i) Conceitos científicos articuladores da área de linguagens, na qual apresenta os conceitos científicos de todos os componentes curriculares constitutivos da área mencionada, dentre as quais está o de Língua Portuguesa/Materna e (ii) As linguagens na formação integral do sujeito: inter-relações no ensino e na aprendizagem, onde, em um movimento de articulação com os fundamentos do documento, faz uma apresentação dos aspectos de cada componente curricular.

O documento adota uma concepção de sujeito que se alinha à Teoria Histórico-Cultural e que, apoiada na Diversidade, defende uma formação integral dos sujeitos. É importante destacar, porém, que o documento se apoia, no capítulo, nas teorias de Gêneros do Discurso e de Letramento para fundamentar suas orientações ${ }^{12}$.

Conforme afirma Bez Fontana (2016, p. 60), é possível observar que o documento “[...] não traz a disciplina de Língua Portuguesa de forma isolada, mas sim como uma unidade de uma área de conhecimento, a área de Linguagens [...]”, ou seja, é apresentada a partir da abordagem teórico-metodológica de interdisciplinaridade.

Quanto às orientações voltadas ao ensino de Portuguesa/Materna, a PCSC as faz com base em conceitos científicos articuladores da área, apresentados na forma de diagrama:

Figura 1. Diagrama com conceitos articuladores da área

${ }^{12}$ As teorias elencadas não serão o foco de discussão neste artigo. 


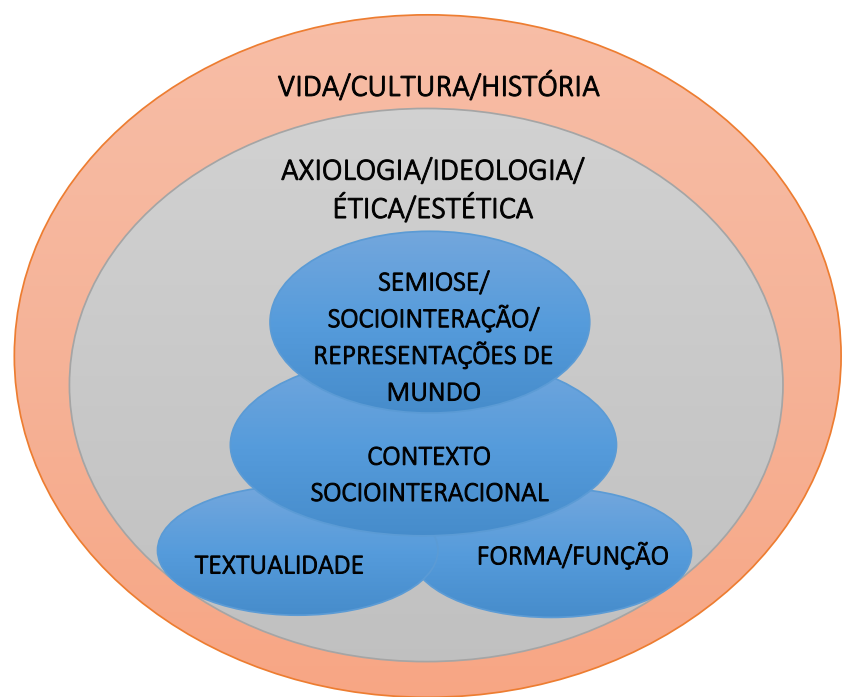

Fonte: Bez Fontana, 2016, p. 64 apud Santa Catarina, 2014, p. 98 [adaptação].

Neste artigo, não iremos abordar a totalidade dos conceitos científicos ${ }^{13}$ trabalhados no capítulo da Área de Linguagens, pois nosso objetivo é, a partir da articulação desses conceitos, apresentar as orientações teórico-metodológicas para o ensino de Língua Portuguesa/Materna registradas no documento.

Com base nos conceitos Vida, Cultura e História, a PCSC conduz sua orientação para uma abordagem de ensino - de língua - que busque realizar uma reflexão sobre as variações de fala evidenciadas em uma mesma língua, juntamente com as características linguísticas de grupos sociais diversos. Dessa forma, o trabalho educativo deve oferecer aos estudantes acesso a espaços culturais diversos, apresentando variedades de fala presentes em sua língua materna, possibilitando assim, uma reflexão sobre a importância do respeito às variedades e o combate à discriminação e ao preconceito linguístico no cotidiano (SANTA CATARINA, 2014).

A partir de Ideologia e Axiologia - conceito depreendido da teoria bakhtiniana -, o documento trata da noção de valor, isto é, a valoração que se atribui às palavras, em sua enunciação, tomadas no intermédio das relações sociointeracionais, destacando traços de tempo, espaço e cultura.

Apoiada nos estudos de Bakhtin, a PCSC orienta para a superação do ensino pautado na gramática, assim, mais que um ensino da forma e/ou da função da língua, o professor deve refletir sobre ela e sobre as relações sociais determinadas pela linguagem. A interação linguística, neste caso, é materializada em gêneros do discurso, estes, presentes na vida

\footnotetext{
${ }^{13}$ Para maior esclarecimento e aprofundamento dos conceitos trabalhados, indicamos a leitura integral da PCSC (2014), disponível em: https://bit.ly/2Lcq9cI e do trabalho de Bez Fontana (2016) disponível em:https://bit.ly/34jqK65
} 
cotidiana e também no universo escolar, entretanto, sem reduzir-se a eles. Assim, o professor possui o importante papel de apontar a concepção de "adequação" dentro dos gêneros, dentre eles, os realizados através de interação nos meios digitais.

O documento orientador, no que compete à relação Forma e Função, defende que o docente deve ser orientado a partir do trabalho com Análise Linguística, buscando sempre uma abordagem que supere por incorporação o tratamento linguístico historicamente engendrado, sem inclinar-se a uma abordagem gramatical normativa e nem a uma abordagem que abandone completamente os conceitos gramaticais. Neste sentido, o trabalho docente deve acontecer a partir das características do sistema linguístico, buscando traçar, a partir da perspectiva sociointeracional, uma compreensão, por parte dos estudantes, da composição lexical de determinado gênero, ou seja, de vocabulário e estrutura gramatical.

A PCSC ainda traz na seção aspectos relacionados à formação de leitores e produtores de texto e aponta para que se tenha muita atenção a estes aspectos da formação, especialmente no que diz respeito ao equilíbrio quando se trata de gêneros discursivos do âmbito da vida cotidiana e da esfera literária, visto que a formação de produtores e leitores não deve ficar apenas na superficialidade, tendo como objetivo a formação meramente para "[...] atendimento a demandas imediatas de sobrevivência e participação social" (SANTA CATARINA, 2014, p. 121).

Desta forma, a PCSC apresenta dois processos fundamentais no âmbito da formação de leitores: a leitura intensiva e a leitura extensiva. A partir dessas duas dimensões do ensino de leitura, o documento procura mostrar que o livro não é o suporte textual exclusivo encarregado pela formação de leitores. Assim, o professor deve considerar os diversos gêneros do discurso como ponto de partida para iniciar um bom trabalho docente, sempre procurando trabalhar a materialização do texto em seu contexto sociointeracional específico, considerando a esfera da atividade humana na qual está circulando, para quem e para qual finalidade foi escrito, dentre outros pontos (SANTA CATARINA, 2014).

Em relação à formação de produtores de textos, o documento orienta para a necessidade de que, para além da superficialidade das características estruturais de cada gênero, o estudante compreenda as especificidades do gênero. Para isso, o professor deve planejar situações em que os estudantes tenham contato prévio com o gênero escolhido, para, posteriormente, iniciar a etapa de produção textual.

De maneira geral, apoiada no conceito de Textualidade, a seção voltada para a área de linguagens, ainda orienta que a formação de leitores e produtores de texto deve ser realizada a 
partir das dimensões social e verbal, alinhadas à teoria bakhtiniana de gêneros do discurso, isto é, deve considerar como alicerce a interação, os contextos históricos e sociais e a estrutura do texto trabalhado. A partir disso, deve-se trabalhar com dois eixos: "compreensão e produção textuais, com o propósito de apropriação/ampliação das práticas sociais de uso da língua" (SANTA CATARINA, 2014, p. 125).

O documento do Estado ainda traz aspectos relevantes ao desenvolvimento da oralidade sob ancoragem, também, da teoria de gêneros do discurso para orientar a superação de práticas que limitam o ensino voltado simplesmente para atividades de decodificação, visando um trabalho com a língua nas práticas sociais (SANTA CATARINA, 2014).

A PCSC, portanto, conduz o docente a realizar um projeto que preze pela "[...] materialização das diferentes semioses nas relações interpessoais [...]" (SANTA CATARINA, 2014, p. 124) e que leve em conta a interação nas e para as atividades humanas, o tempo histórico e os espaços socioculturais onde os textos se materializam. Para tal, Bez Fontana (2016, p. 131) salienta que "este trabalho exige dos professores uma sólida base de conhecimentos acerca da língua, o que preconiza uma boa formação inicial e continuada".

Por fim, as orientações teórico-metodológicas da Proposta Curricular de Santa Catarina (2014) devem/deveriam contemplar as especificidades da modalidade de Educação de Jovens e Adultos. Neste sentido, o documento afirma que as orientações postuladas devem ser endereçadas "[...] para os processos educacionais na alfabetização de jovens, adultos e idosos, respeitadas as características de sua historicidade no percurso formativo" (SANTA CATARINA, 2014, p. 124). É necessário registrar, contudo, que a modalidade tema do presente artigo não possui tratamento específico no decorrer do documento, ainda que mencionadas por toda a sua extensão.

\subsection{ATUALIZAÇÃO DA PROPOSTA: CURRÍCULO BASE DA EDUCAÇÃO DO TERRITÓRIO CATARINENSE (2019)}

Visto que a Proposta Curricular de Santa Catarina sofreu uma atualização no final de 2019, é de grande importância ressaltar que o documento passou a ser intitulado: Currículo Base da Educação Infantil e do Ensino Fundamental do Território Catarinense e, diferentemente do documento anterior, foi organizado textualmente a partir dos grupos de trabalhos específicos de cada área. O documento de 2014, também escrito a partir do trabalho coletivo de professores 
e consultores, é organizado em um texto único; já a nova versão conta com o nome dos autores após o título de cada seção.

Em contraste com o documento apresentado em 2014, a nova versão possui uma seção específica para tratar da Educação de Jovens e Adultos, que está ancorada nas competências gerais apresentadas pela Base Nacional Comum Curricular ${ }^{14}$ e é baseada no texto, também publicado em 2019, Educação de Jovens, Adultos(as) e Idosos(as) (EJA): princípios filosóficos, legais e curriculares para a Educação de Jovens e Adultos no território catarinense.

O documento em questão aponta a oferta de educação de jovens e adultos em espaços de privação de liberdade no Estado, mas deixa claro que não é realizado um debate sobre as especificidades educativas desses espaços e propõe que o texto seja lido pelos profissionais que atuam no contexto, pois pode contribuir, de certo modo, na construção dos planejamentos e propostas pedagógicas.

A seção aponta a Atividade Orientadora de Ensino, a partir de Moura (2001), como possibilidade de organização pedagógica, que é constituída a partir de Unidades Temáticas, considerando os conhecimentos relevantes que atendem às especificidades dos estudantes.

O documento também apresenta uma atualização para a área de Linguagens, juntamente com um apêndice com diversos quadros para a organização curricular, abrangendo do primeiro ao nono ano do Ensino Fundamental, deixando de fora o Ensino Médio e EJA.

\section{PLANO ESTADUAL DE EDUCAÇÃO EM PRISÕES (2016-2026)}

Assim como diversos campos da sociedade civil, o âmbito da educação em espaços de privação de liberdade também possui seu plano de ação, este, desenvolvido de forma coletiva, por consultores, a fim de difundir metas e estratégias para ampliação e melhoria da oferta de educação nesses espaços por todo o Estado de Santa Catarina.

O documento intitulado Plano Estadual de Educação em Prisões 2016-2026: educação, prisão e liberdade, diálogos possíveis - PEEP/SC foi publicado em 2017 e possui como vigência final o ano de 2026 e tem como objetivo contribuir com a universalização da educação e dos direitos humanos, oferecendo acesso à educação nos espaços de privação e restrição de liberdade, para que os apenados possam exercer, de forma efetiva, seus direitos como cidadãos (SANTA CATARINA, 2017).

\footnotetext{
${ }^{14}$ Neste artigo, não discutiremos as problemáticas que cercam a publicação da BNCC, para tal, indicamos, para aprofundamento acadêmico, a leitura de Gontijo (2015) Base Nacional Comum Curricular (BNCC): comentários críticos e Gontijo, Costa \& Perovano (2020) Alfabetização na Base Nacional Comum Curricular (BNCC).
} 
Inicialmente, o referente documento apresenta a concepção de educação na qual está alinhado, tomada como desenvolvida no decorrer da vida dos sujeitos e que se realiza dentro e fora do contexto escolar. Assim, seguindo a orientação da PCSC, o PEEP/SC apresenta, de maneira didática, a concepção de formação integral, que, em tese, tem como objetivo o desenvolvimento humano pautado no conhecimento historicamente acumulado.

Para integrar sua fundamentação, o documento procura trazer uma reflexão acerca da visão de uma EJA como modalidade compensatória (SAVIANI, 2007 [1983]), visão já ultrapassada, e afirma o Ensino de Jovens e Adultos como direito fundamental "para a construção de uma 'cultura da paz e da educação para a cidadania e democracia"” (PAIVA, MACHADO \& IRELAND, 2004, p.46 apud SANTA CATARINA, 2017, p. 26).

Quanto à oferta de ensino no sistema prisional do Estado, o documento deixa claro que, para além das perspectivas criadas com a Educação de Jovens e Adultos, o corpo de gestores deve ter consciência que o sistema penitenciário possui particularidades que devem ser consideradas e contempladas em suas propostas educacionais (SANTA CATARINA, 2017).

O referente apresenta a prisão a partir de uma visão de uma prisão que educa, que, segundo o documento, "[...] é muito próxima da concepção de uma educação integral, mas que, ao mesmo tempo, seja integrada e integradora [...]" e propõe a modalidade de ensino com professores que possuem “[...] formação específica, material didático pedagógico próprio e métodos e técnicas de ensino adequadas ao contexto prisional" (SANTA CATARINA, 2017, p. 28).

O Plano trata, também, das formações inicial e continuada dos profissionais, que atuam na esfera educacional, presentes no ambiente carcerário do Estado, e destaca um dos maiores obstáculos enfrentados por estudantes de graduação das licenciaturas, a falta de disciplinas voltadas à educação de jovens e adultos e frisa que a qualidade da formação dos profissionais que optam por mediar, através dos objetivos da educação, os objetivos da prisão:

\footnotetext{
Os cursos de graduação, das universidades públicas e privadas de Santa Catarina, não contemplam em seu currículo disciplinas voltadas à modalidade de Educação de Jovens e Adultos - EJA, no entanto oferecem disciplinas optativas específicas para esta modalidade. Por outro lado, as universidades públicas e privadas do estado têm professores orientadores, nos cursos de pós-graduação, que se propõem orientar trabalhos dirigidos à EJA e à educação prisional. (SANTA CATARINA, 2017, p. 68, grifo nosso)
}

$\mathrm{O}$ PEEP/SC orienta que as práticas pedagógicas e de atendimento às diversidades devem ter como base as orientações da Proposta Curricular, a qual organiza o percurso formativo a 
partir das especificidades do corpo de estudantes, dando autonomia aos sujeitos, para que possam desempenhar, da melhor forma, sua função social. Destarte, a partir do Atendimento às Diversidades leva em consideração as particularidades do ambiente de privação de liberdade, valoriza as diferenças e experiências individuais, oferecendo ao apenado uma oportunidade de conhecimento sem referenciais e pré-conceitos, o educando será compreendido por si só (SANTA CATARINA, 2017).

Em síntese, o PEEP/SC se propõe a fazer uma transposição das orientações propostas na PCSC (2014) no que se refere à formação integral dos indivíduos e ao atendimento às diversidades. $\mathrm{O}$ documento, contudo, se mantém na superficialidade quanto às orientações teórico-metodológicas e pedagógicas.

Além desse aspecto, frisamos a importância do plano de ação elaborado pelo Estado, porém, a produção de um documento orientador, voltado para as especificidades do sistema prisional catarinense também é de significativa importância, visto que o documento não contém orientações para o ensino de Língua Portuguesa/Materna voltadas para a educação nesses espaços e, não há, por ora, no Estado de Santa Catarina, documento que o faça levando em consideração às especificidades da "modalidade".

\section{PROJETO POLÍTICO-PEDAGÓGICO DO CEJA FLORIANÓPOLIS}

O Projeto Político Pedagógico (PPP) é um dos principais documentos que orientam a educação, seja ela dentro ou fora dos espaços de privação de liberdade do Estado. Este documento, segundo determinação da Lei de Diretrizes e Bases da Educação Nacional - LDB (BRASIL, 1996), deve ser elaborado e atualizado anualmente por todas as escolas ${ }^{15}$.

A fim de aproximar o leitor à realidade dos documentos orientadores, apresentaremos, nesta seção, as indicações do PPP da Unidade Descentralizada do CEJA, presente na penitenciária de Florianópolis.

Inicialmente, o referente analisado defende, para a implementação da oferta de educação na unidade prisional, ser “[...]necessária a articulação entre equipe pedagógica e administrativa da Coordenadoria Regional da Grande Florianópolis, do CEJA de Florianópolis e da Unidade Prisional" para que então se possa definir as metodologias e condições de estudo no local (FLORIANÓPOLIS, 2018, p. 13).

\footnotetext{
${ }^{15}$ Documento elaborado, neste caso, pelo CEJA-Centro.
} 


\section{Linguagens - Revista de Letras, Artes e Comunicação - ISSN 1981- 9943 \\ Blumenau, v. 15, n. 3, p. 004-024, set./dez. 2021.}

Em relação aos pressupostos teórico-filosóficos sustentados pelo CEJA-Florianópolis, é possível inferir a orientação construtivista de educação, numa tentativa de combinação com a concepção histórico-cultural:

O Centro de Educação de Jovens e Adultos tem como pressuposto filosófico, possibilitar ao aluno o saber elaborado, socialmente reconhecido de maneira que, ao construir em si mesmos novos conhecimentos, seja seu próprio agente transformador, contribuindo expressivamente para o desenvolvimento social, certificando escolarização de estudos da Educação Básica (Ensino Fundamental e Médio). (FLORIANÓPOLIS, 2018, p.14, grifo nosso)

Parece haver, em expressão ao fragmento do documento em tela, um enovelamento com uma concepção histórico-social do desenvolvimento humano, na medida em que, pareada à identificação de algum apreço pela escolarização a partir de saberes previamente adquiridos, considerando esses indivíduos como sujeitos historicizados, o PPP registra a tentativa de contextualizar e organizar esses conhecimentos com o propósito de formar indivíduos que se desenvolvam socialmente a partir do saber elaborado.

É de grande importância destacar, também, que um dos objetivos do CEJA de Florianópolis é "resgatar a escolaridade do jovem e do adulto no Ensino Fundamental e Médio, que foi interrompida durante anos, visando reparar e propiciar ao aluno um ensino voltado para as necessidades imediatas" (FLORIANÓPOLIS, 2019, p. 16).

Nesta perspectiva, o PPP traz à tona a modalidade como de educação compensatória, perspectiva que o PEEP/SC busca superar. No que se refere à perspectiva pedagógica elencada pelo PPP, Saviani (2007) afirma que é atribuída à ação pedagógica, na expressão "educação compensatória", a responsabilidade de compensar todo o tipo de carência que caracterize a situação de marginalidade das camadas populares e do fracasso escolar:

Educação compensatória significa, pois, o seguinte: a função básica da educação continua sendo interpretada em termos da equalização social. Entretanto, para que a escola cumpra sua função equalizadora é necessário compensar as deficiências cuja persistência acaba sistematicamente por neutralizar a eficácia da ação pedagógica. (SAVIANI, 2007, p. 36)

Em conclusão, no que se refere às orientações para o ensino de Língua Portuguesa/Materna, não há, no documento, seção voltada para a área, o qual apenas busca tal relação quando discorre sobre um de seus objetivos: "preparar o aluno para utilizar os diferentes códigos de linguagem, para bem se comunicar e interpretar a realidade que o cerca" (FLORIANÓPOLIS, 2019, p. 16). 
Ressaltamos, ainda, que para além de diversas outras problemáticas encontradas no decorrer do documento, este não contempla plenamente a Resolução n 110/2012 do Conselho Estadual de Educação (SANTA CATARINA, 2012), que orienta a construção de um PPP que leva em consideração as especificidades do sistema penitenciário em questão, as necessidades e os interesses dos alunos ali presentes, juntamente com uma articulação entre as culturas e os aspectos gerais de ensino e aprendizagem, pois não há, no documento, um capítulo específico sobre as demandas específicas da Escola da Penitenciária de Florianópolis.

\section{CONSIDERAÇÕES FINAIS}

Conforme afirmamos no início do trabalho, apresentamos, neste artigo, as indicações teórico-metodológicas para o ensino de Língua Portuguesa/Materna nos espaços de privação de liberdade do Estado de Santa Catarina, contidas nos documentos orientadores, com o intuito de aproximar os futuros docentes e pesquisadores da área, com a Educação de Jovens e Adultos nesses espaços.

Inicialmente, a partir dos marcos legais que norteiam a educação nos espaços de privação de liberdade, é possível perceber o percurso que se desenvolveu, até começarmos a ter um efetivo encaminhamento para a implementação de políticas públicas voltadas à necessidade desses espaços. Porém, conforme postula Julião (2013), foi apenas a partir de 2005 que se iniciaram as movimentações para a implementação de políticas públicas voltadas ao ensino para o sistema penitenciário nacional, mesmo que estudos mostrem que a elaboração de leis é mais antiga que isso.

Em Santa Catarina, observa-se que há certo movimento em prol de adequações e de uma política regulamentadora para esses espaços, embora ainda haja grande divergência quanto aos pressupostos filosóficos e teórico-metodológicos dos documentos que permeiam a educação em espaços de privação de liberdade, que pôde ser observada a partir da análise documental comparativa realizada no processo de apresentação, dos documentos orientadores.

Para além da problemática ${ }^{16}$, podemos citar impasses que ocorrem desde a contratação de professores temporários para modalidade de ensino presente nos espaços de privação de

\footnotetext{
16 Indica-se, ainda, para um contato mais profundo, acerca da discussão das problemáticas que envolvem as questões voltadas à educação nos espaços de privação de liberdade de Santa Catarina, a leitura dos trabalhos de Nakayma (2011) "O Trabalho de professores/as em espaço de privação de liberdade: necessidades de formação continuada"; Garcia (2018) "Cultura escrita e educação escolar em espaço de privação de liberdade: (im)possibilidades de uma formação humana integral” e Narciso (2019) "Ensino de língua na Educação de Jovens e Adultos em situação de privação de liberdade: elementos para pensar a formação humana a partir de uma abordagem histórico-cultural".
} 
liberdade de Santa Catarina; a necessidade de formação continuada específica para a área; a falta de estrutura física desses espaços; a deficiência de vagas ofertadas, até a carência de regulamentações que implementam o EJA nas penitenciárias no Estado, como bem podem ser observadas no PEEP/SC (2017) e no Relatório Mensal do Cadastro Nacional de Inspeções nos Estabelecimentos Penais e no Painel Interativo do Levantamento Nacional de Informações Penitenciárias.

Destacamos, neste momento, que o Estado ainda precisa, de forma urgente, trabalhar para uma discussão mais profunda e específica acerca das particularidades desses espaços, visando efetiva elaboração de um documento específico que oriente teórico-metodologicamente a Educação de Jovens e Adultos em situação de privação de liberdade, obedecendo a Lei Complementar 170/1998, tendo em vista, também, que a assistência à pessoa privada de liberdade é dever dele.

Assim, como afirma Julião (2013)

\begin{abstract}
Embora consigamos destacar alguns avanços concretos, por outro lado, percebemos que precisamos muito ainda avançar no campo normativo. Necessitamos principalmente investir na consolidação das diretrizes nacionais. Não é mais concebível que estados ainda não possuam uma política regulamentada para estas ações, evidenciando-se, em várias unidades, projetos isolados, sem fundamentação teórico-metodológica, sem qualquer continuidade administrativa, beirando o total improviso de espaço, gestão, material didático e atendimento profissional. (JULIÃO, 2013, p. 397)
\end{abstract}

Com relação às orientações teórico-metodológicas voltadas à educação nos espaços de privação de liberdade do Estado de Santa Catarina, destacamos as referências bibliográficas de destaque presentes nos documentos, quando se trata das especificidades da modalidade educacional. Entretanto, a ausência de orientações para o ensino de Língua Portuguesa/Materna neles é um aspecto que sobressai a análise documental, já que são escassos os encaminhamentos para o trabalho com linguagem - além das orientações da PCSC e do vago direcionamento do PPP e, quando presentes, frágeis teórico-epistemologicamente, dada a grande mistura de concepções teóricas presentes nos documentos e do distanciamento da concepção formação humana integral presente na Proposta Curricular do Estado de 2014.

Em virtude disso, destacamos a problemática que envolve a falta de indicações para o trabalho com linguagem que englobe as especificidades do contexto e que oferte indicações metodológicas que vise uma educação justa, igualitária, de qualidade e que busque contribuir para a humanização dos sujeitos. Assim, é urgente que o Estado invista efetivamente na 
elaboração de uma proposta curricular que contemple os aspectos característicos dos espaços de privação de liberdade, que ainda não é contemplado em sua última atualização.

Ademais, a partir das problemáticas apresentadas, os apontamentos de Saviani (2013) para a crescente descaracterização trabalho escolar como resultado da não caracterização de um currículo escolar consistente e bem definido, com suas atividades curriculares e extracurriculares delineadas e que busque, efetivamente a transmissão-assimilação de conhecimentos sistematizados podem contribuir para pensar a elaboração de uma proposta curricular para o Estado de Santa Catarina que permaneça coerente em relação ao fundamento teórico-filosófico já sustentado pelos documentos desde a década de 1990 e que viabilize condições para transmissão e assimilação do saber elaborado aos sujeito, com vistas à uma formação humana integral. 


\section{REFERÊNCIAS}

ALVISI, Cátia; PACHECO E ZAN, Dirce Djanira. Cárcere, Currículo e o Cotidiano Prisional: desafios para o direito humano à educação. Políticas Educativas - Poled, Porto Alegre, v. 5, n. 1, p.32-44, 2011. Semestral. Disponível em: https://seer.ufrgs.br/Poled/article/view/35731/23233. Acesso em: 03 out. 2019.

BEZ FONTANA, Josiane. Eixos teóricos constitutivos do componente de língua portuguesa na rede estadual de Santa Catarina: novas reflexões. [s.l: s.n.]. 2016. Disponível em: http://www.bu.ufsc.br/teses/PPLE0014-D.pdf. Acesso em: 10 set. 2019.

BRASIL. Consulta ao Índice de Desenvolvimento da Educação Básica - Ideb. Brasília: Instituto Nacional de Estudos e Pesquisas Educacionais Anísio Teixeira, 2019. Disponível em: http://ideb.inep.gov.br/resultado/. Acesso em: 14 out. 2020

BRASIL. Ministério da Educação. Secretaria de Educação Fundamental. Proposta Curricular para a educação de jovens e adultos: segundo segmento do ensino fundamental: 5a a 8a série. Secretaria de Educação Fundamental, 2002. 256 p.

BRASIL. Constituição (1988). Constituição da República Federativa do Brasil. Brasília, DF: Senado Federal: Centro Gráfico, 1988. 292 p. Disponível em:

http://www.planalto.gov.br/ccivil_03/constituicao/constituicao.html. Acesso em 24 jan. 2019.

BRASIL. Congresso. Senado. Lei no 7.210, de 11 de julho de 1984. Institui a Lei de Execução Penal. Brasília, Disponível em:

http://portal.mec.gov.br/index.php?option=com_docman\&view=download\&alias=10029-lei7210-11-julho-1984\&category_slug=fevereiro-2012-pdf\&Itemid=30192. Acesso em: 23 jan. 2019.

BRASIL. Congresso. Senado. Lei $\mathbf{n}^{\mathbf{0}}$ 3.274, de 2 de outubro de 1957. Dispõe sobre Normas Gerais do Regime Penitenciário, em conformidade do que estatui o art. $5^{\circ}, n^{\circ} \mathrm{XV}$, letra "b", da Constituição Federal, e amplia as atribuições da Inspetoria Geral Penitenciária. Brasília, Disponível em: https://bit.ly/3g5jqPA. Acesso em: 23 jan. 2019.

BRASIL. LDB: Lei de diretrizes e bases da educação nacional: Lei n.9.394, de 1996. Brasília, DF: [s.n], 1997. Brasília: Secretaria Especial de Editoração e Publicações. Disponível em: http://www.planalto.gov.br/ccivil_03/LEIS/L9394.html. Acesso em 28 jan. 2019.

BRASIL, CNJ, GEOPRESÍDIOS - Relatório Mensal do Cadastro Nacional de Inspeções nos Estabelecimentos Penais. 1.0.0. [S. 1.], 2014. Disponível em: https://www.cnj.jus.br/inspecao_penal/mapa.php. Acesso em: 29 jun. 2020.

CEE, Conselho Estadual de Educação de Santa Catarina. Resolução no 110, de 28 de agosto de 2012. Dispõe sobre as Diretrizes operacionais para a oferta de educação para jovens e adultos em situação de privação de liberdade nos estabelecimentos penais do Estado de Santa Catarina. Florianópolis, SC, Disponível em: http://www.cee.sc.gov.br/index.php/downloads/comissoes/educacao-basica/educacao-dejovens-e-adultos/resolucoes-11/853-853/file. Acesso em: 24 jan. 2019. 
FLORIANÓPOLIS. PPP, Projeto Político-pedagógico do CEJA Florianópolis/SC. 2018. 52p. Disponível em:

https://docs.google.com/document/d/1OpfMeKZeHqpX7x9tXyh8zzAb0cXqiP2ZKPFTb62_E Wc/edit?usp=sharing. Acesso em 28 jan. 2019.

FLORIANÓPOLIS. PPP. Projeto Político-pedagógico do CEJA Florianópolis/SC. 2019. 52p. Disponível em:

https://docs.google.com/document/d/1TGKXVHRaI2Ds2MvFwlVeNcrVvfkOCEt7Nssa_ED 0rho/edit?usp=sharing. Acesso em 09 set. 2019.

GARCIA, Daniela Cristina da Silva. Cultura escrita e educação escolar em espaço de privação de liberdade: (im)possibilidades de uma formação humana integral. 2018. 221 p. Disponível em: http://www.bu.ufsc.br/teses/PLLG0736-D.pdf. Acesso em: 10 set. 2019.

GAMBOA, Silvio Sánchez. Pesquisa em educação: métodos e epistemologias. 3. ed. rev., atual. e ampl. Chapecó, SC: Argos, 2018.

GONTIJO, C. M. M. Base Nacional Comum Curricular (BNCC): comentários críticos. Revista Brasileira de Alfabetização, 2015, p 174-190. Disponível em: http://revistaabalf.com.br/index.html/index.php/rabalf/article/view/68/51. Acesso em 27 jun. 2020 .

GONTIJO, Cláudia Maria Mendes; COSTA, Dania Monteiro Vieira; PEROVANO, Nayara Santos. Alfabetização na Base Nacional Comum Curricular (BNCC). Pro-Posições, Campinas, v. 31, 22 abr. 2020. Disponível em: https://www.scielo.br/j/pp/a/SSfgKgXvXK5VDq6GqfGfwhK/?lang=pt. Acesso em: 26 jun. 2020.

JULIÃO, Elionaldo Fernandes (org.). Educação para Jovens e Adultos em situação de restrição e privação de liberdade: Questões, avanços e perspectivas. 1.ed. eBook. Jundiaí, SP. Paco Editorial. 2013.

MOURA, Manoel. Oriosvaldo. de. A atividade de ensino como ação formadora. In: CASTRO, Amelia. Domingues. de; CARVALHO, Anna. Maria. Pessoa. de. (orgs.). Ensinar a ensinar: Didática para a escola fundamental e média. São Paulo: Pioneira Thompson Learning, 2001. p. 143-162.

NARCISO, Carolina Fabricia. Ensino de língua na Educação de Jovens e Adultos em situação de privação de liberdade: elementos para pensar a formação humana a partir de uma abordagem histórico-cultural. Trabalho de Conclusão de Curso de Graduação em Língua Portuguesa e Literaturas. Florianópolis: Universidade Federal de Santa Catarina. 2019. 57 p. Disponível em: https://repositorio.ufsc.br/handle/123456789/203429. Acesso em: 27 jun. 2020.

SANTA CATARINA. Proposta Curricular de Santa Catarina: formação integral na educação básica. Florianópolis, SED, 2014. 192 p. Disponível em:

http://www.sed.sc.gov.br/documentos/ensino-89/proposta-curricular-156/4326-propostacurricular-final. Acesso em 09 set. 2019. 
SANTA CATARINA. Currículo Base da Educação Infantil e do Ensino Fundamental do Território Catarinense. Florianópolis, SED, 2019. 473 p. Disponível em:

http://www.sed.sc.gov.br/professores-e-gestores/30440-curriculo-base-da-educacao-infantile-do-ensino-fundamental-do-territorio-catarinense-3. Acesso em 09 set. 2019.

SANTA CATARINA. Secretaria de Estado da Educação. Secretaria de Estado da Justiça e Cidadania. Plano estadual de educação em prisões 2016-2026: educação, prisão e liberdade, diálogos possíveis. CARDENUTO, Heloisa Helena Reis (org.) - Florianópolis: DIOESC, 2017. 92p. Disponível em: http://www.sed.sc.gov.br/documentos/programaprivacao-espacos-de-liberdade/legislacao-estadual-2/6152-plano-estadual-de-educacao-emprisoes-online-ioesc/file. Acesso em 24 jan. 2019.

SANTA CATARINA (Estado). Lei Complementar $\mathbf{n}^{\mathbf{0}} \mathbf{2 6 3}$, de 23 de janeiro de 2004. Altera a Lei Complementar No 170, DE 1998, que dispõe sobre o sistema estadual de educação.

Florianópolis, SC, Disponível em:

http://leis.alesc.sc.gov.br/html/2004/263_2004_lei_complementar.html. Acesso em: 24 jan. 2019.

SANTA CATARINA (Estado). Lei Complementar $\mathbf{n}^{\mathbf{0}}$ 263, de 23 de janeiro de 2004. Altera a Lei Complementar Nº 170, DE 1998, Que dispõe sobre o sistema estadual de educação. Florianópolis, SC, Disponível em:

http://leis.alesc.sc.gov.br/html/2004/263_2004_lei_complementar.html. Acesso em: 24 jan. 2019.

SANTA CATARINA, Conselho Estadual de Educação de Santa Catarina. Resolução n⿳0 110, de 28 de agosto de 2012. Dispõe sobre as Diretrizes operacionais para a oferta de educação para jovens e adultos em situação de privação de liberdade nos estabelecimentos penais do Estado de Santa Catarina. Florianópolis, SC, Disponível em:

http://www.cee.sc.gov.br/index.php/downloads/comissoes/educacao-basica/educacao-dejovens-e-adultos/resolucoes-11/853-853/file. Acesso em: 24 jan. 2019.

SAVIANI, Dermeval. Escola e democracia. 39. ed. Campinas: Autores Associados, 2007.

SAVIANI, Dermeval. Pedagogia histórico-crítica: primeiras aproximações. 11. ed. rev. Campinas: Autores Associados, 2013. 137 p. (Coleção educação contemporânea). ISBN 9788574963242. Disponível em: https://b-ok.lat/book/11284435/2c6ae2. Acesso em: 13 dez. 2021.

VYGOTSKY. L. S. Obras escogidas V. Madrid: Centro de Publicaciones Del MEC y Visor Distribuciones, 1997

Submetido: 26/05/2021 Aceito: 19/12/2021 